\title{
Numerical investigation of heat losses through cascaded fully open cavity receiver at high temperatures up to $500^{\circ} \mathrm{C}$
}

\author{
Kushal Wasankar ${ }^{1 *}$, Shreyas Yadav $^{1}$, Ramola Sinha ${ }^{1,2}$, Nitin Gulhane ${ }^{1}$ \\ ${ }^{1}$ Mechanical Engineering Department, Veermata Jijabai Technological Institute, Mumbai 400 019, India \\ ${ }^{2}$ Mechanical Engineering Department, K. J. Somaiya College of Engineering, Mumbai 400 072, India
}

\begin{abstract}
In solar thermal systems, especially for high concentration applications, natural convection and radiation contributes a significant fraction of energy loss. Its characteristics hence need to be understood to improve system efficiency. In this work a numerical study is carried out to investigate the heat loss through a cascaded cavity receiver of a solar dish collector. The effect of increase in area ratio on heat loss is studied. The cascaded cavity receiver model is electrically heated with constant heat flux. A simulation model for combined natural convection and surface radiation is developed. The influence of orientation of the receiver, and the geometry on total heat loss from the receiver is investigated. The cavity inclination is varied from $0^{\circ}$ to $90^{\circ}$ in steps of $30^{\circ}$. The Computational Fluid Dynamics package "ANSYS 19.2 Fluent" has been used to numerically investigate the influence of cavity geometry and inclination on the convective loss through the aperture. The cascaded cavity receiver is found to reduce the natural convection and radiation heat losses.
\end{abstract}

Keywords: Natural convection, solar cavity receiver, heat loss, numerical study, cascaded cavity

\section{INTRODUCTION}

The concentrating solar technology has the potential to be used for supplying industrial process heat as well as for generating power. The parabolic dish-receiver assembly is one such promising system. The parabolic dish-receiver assembly usually consists of a reflector in the form of a dish whose geometry allows reflecting the incident solar rays at the downward facing receiver, placed at the focus of the dish. Generally, a cavity receiver is used since it can maximize the absorption of the concentrated flux and minimize heat losses. The heat losses include convective and radiative losses through the opening of the cavity and conduction through the supporting structure and through the insulation used behind the cavity surfaces. The overall efficiency of such systems is dependent on the thermal losses occurring from the cavity receiver. Generally, the loss due to conduction is quite small and can easily be neglected [1]. The radiative loss is dependent on the cavity wall temperature, the shape factor and emissivity of the walls. It is observed from the literature that the convective heat transfer constitutes a major share of the thermal losses [2] [3] [4]. The convective losses from these solar cavity receivers are found to be dependent on various parameters like receiver inclination $(\theta)$, receiver wall boundary condition, aspect ratio (L/D), opening ratio (d/D), and external wind. This is the reason due to which analysis of convective losses from solar cavity receivers is complicated when compared to that of heat loss due to radiation and conduction [5] .

The investigations on convective losses from open cavities (cubical, rectangular and square) have been carried out by a number of research groups. In these investigations, the cavity walls are either uniformly heated or one wall is heated and others are maintained at adiabatic conditions. Initial research on this topic focused on cubical cavity receivers. Eyler (1981) [6] carried out a 2-dimensional numerical analysis of convective losses in rectangular and hemispherical solar cavity receiver respectively. His results confirmed the dependency of convective loss on cavity dimensions and wall temperature. Clausing [7] was the first to propose an analytical model for convection loss, which took in to consideration the presence of two distinct regions within cavities, namely a (i) stagnation zone and a (ii) convective zone. He hypothesized that convective heat loss depended on two main factors; 1 ) the ability to transfer mass and energy across the aperture, and 2) the ability to heat the air inside the cavity. Subsequent work by Clausing [7] used experimental data to provide more accurate correlations.

A correlation of experimental Nusselt number for isothermal open cubical cavity for different angles of inclination were presented by LeQuere et al. [8]. Taumoefolau et al. [4] investigated the natural convection heat loss from an electrically heated model cavity receiver for different inclinations varying from $\theta=-90^{\circ}$ (cavity facing up) to $\theta=+90^{\circ}$ (cavity facing down) with temperature ranging from $450^{\circ} \mathrm{C}$ to $650^{\circ} \mathrm{C}$. It was in their investigation, where natural convection heat loss at $90^{\circ}$ inclination existed, which contradicted other models. Sendhil and Reddy [3] carried out a comparative study of semicavity, cavity, and modified cavity receivers. They also developed the 2D natural convection heat loss model for modified cavity receiver of two different

*Correspondence author: wasankark@gmail.com 
configurations. Natural convection heat loss was observed at $90^{\circ}$ inclination of the receiver for both the receiver.

Balaji and Venkateshan [9] reported the numerical results of the fundamental problem of interaction of surface radiation with laminar free convection in an open cavity with air as the intervening medium. The basic flow pattern as well as overall thermal performance is altered by surface radiation of the open cavity. A comparison of the numerical and experimental observations showed that the accurate prediction of the flow and thermal field influenced by radiation heat transfer. An experimental study for the combined natural convection and radiation heat transfer in a cavity with top opening was carried out by Ramesh and Merzkirch [10]. The study showed that the flow and temperature patterns were significantly influenced by emissivity of the cavity wall. A numerical study of combined laminar natural convection and surface radiation heat transfer in a 2D side vented open cavity for different aspect ratios, side-vent ratios and surface emissivities using air as the working fluid was carried out by Singh and Venkateshan [11] and based on their study, several Nusselt number correlations were developed for convective and radiative heat transfer. Hinojosa et al. [12] presented the numerical results of the heat transfer by natural convection and surface thermal radiation in a tilted 2D open cavity. Separate correlations were developed by Balaji and Venkateshan [13] for both convective and radiative heat transfer in a square cavity with air as the intervening medium. Sendhil and Reddy [14] investigated the effects of inclination and emissivity of the receiver on combined natural convection and surface radiation heat transfer.

In the present study, a 2D numerical model with a steady state combined laminar natural convection and surface radiation heat transfer from a modified cylindrical cavity receiver of a solar parabolic dish system for various orientations has been developed.

\section{NUMERICAL ANALYSIS}

2.1 Problem formulation: The CFD Software Package Fluent 19.2 is being employed in the $2 \mathrm{D}$ simulation of the combined natural convection and surface radiation heat transfer.

The model receiver consist of a stainless steel - 316 cascaded cylindrical cavity receiver, with an internal diameters of $83 \mathrm{~mm}$ and $67 \mathrm{~mm}$ for external and internal cylinder respectively, with a wall thickness of $3 \mathrm{~mm}$. The lengths of the two cascaded cylinders are $169 \mathrm{~mm}$ and 110 $\mathrm{mm}$ for external and internal cylinder respectively. Fig. 1 illustrate the cross sections and relevant dimensions of the receivers considered for study. The length of the inner cylinder is so considered as to double the area ratio.

In reality the receiver is surrounded by an infinite atmosphere with a limiting temperature equal to ambient air. To model this condition in the CFD analysis, the flow domain is established such that the receiver is placed in a sufficiently large enclosure with walls at ambient temperature as schematically shown in Fig. 2.

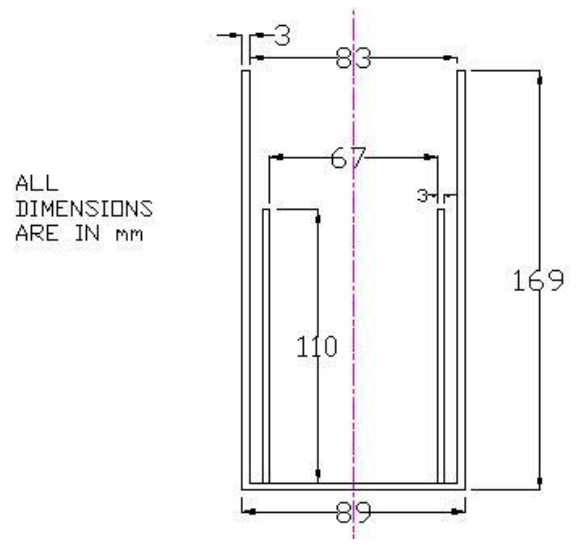

Figure 1 Cavity Geometry

According to Eyler [6] as long as the exterior region of the cavity extended beyond a distance equal to the interior cavity depth, the effect on flow and heat transfer inside the receiver was negligible. However, in this study the diameter of the cylindrical enclosure used is fifteen times the diameter of the receiver to make sure that the effect on the predicted fluid and heat flows are insignificant as suggested in literature.

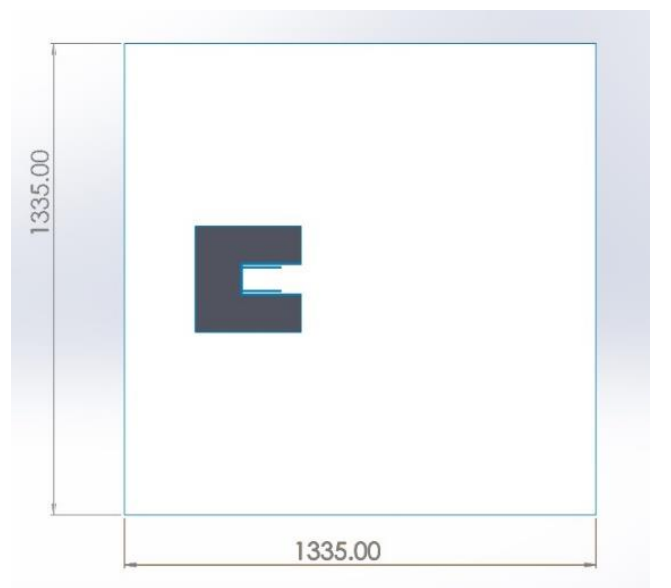

Figure 2 Computational domain used (dimensions are in $\mathrm{mm}$ )

The receiver geometry is cylindrical and covered with a cylindrical insulation which has a outer dimensions of $300 \mathrm{~mm}$ diameter and $300 \mathrm{~mm}$ length. The present study requires $3 \mathrm{D}$ analysis of the modified cavity receiver. Separate 2D and 3D simulations were carried out at $90^{\circ}$ inclinations of the receiver. It was found that the $3 \mathrm{D}$ simulations predict slightly better than that of the 2D simulations. However, the computational time and grid size involved in 3D are respectively 5 times and 15 times higher than 2D. Therefore, a 2D model has been adopted in the present study to predict the total heat loss from the receiver with little approximation.

2.2 Modelling Equations: The flow and heat transfer simulations were based on the simultaneous solution of the 
system of equations describing the conservation of mass, momentum and energy [15]. These equations can be expressed for an incompressible fluid as given below.

To account for the radiation exchange in an internal surface of the modified cavity receiver along with the natural convection heat loss, S2S model is chosen in the present numerical procedure. The S2S model is coupled with the laminar natural convection model. In the S2S radiation model, the surfaces are taken as gray and diffused.

$$
\begin{aligned}
& \frac{\partial(\rho u)}{\partial x}+\frac{\partial(\rho v)}{\partial x}+\frac{\partial(\rho w)}{\partial x}=0 \\
& \rho\left[u \frac{\partial(u)}{\partial x}+v \frac{\partial(u)}{\partial y}+w \frac{\partial(u)}{\partial z}\right] \\
& =\rho g_{x}-\frac{\partial(p)}{\partial x} \\
& +\mu\left[\frac{\partial^{2} u}{\partial x^{2}}+\frac{\partial^{2} u}{\partial y^{2}}+\frac{\partial^{2} u}{\partial z^{2}}\right] \\
& \rho\left[u \frac{\partial(v)}{\partial x}+v \frac{\partial(v)}{\partial y}+w \frac{\partial(v)}{\partial z}\right] \\
& =\rho g_{y}-\frac{\partial(p)}{\partial y} \\
& +\mu\left[\frac{\partial^{2} v}{\partial x^{2}}+\frac{\partial^{2} v}{\partial y^{2}}+\frac{\partial^{2} v}{\partial z^{2}}\right] \\
& \rho\left[u \frac{\partial(w)}{\partial x}+v \frac{\partial(w)}{\partial y}+w \frac{\partial(w)}{\partial z}\right] \\
& =\rho g_{z}-\frac{\partial(p)}{\partial z} \\
& +\mu\left[\frac{\partial^{2} w}{\partial x^{2}}+\frac{\partial^{2} w}{\partial y^{2}}+\frac{\partial^{2} w}{\partial z^{2}}\right] \\
& \rho C_{p}\left[u \frac{\partial T}{\partial x}+v \frac{\partial T}{\partial y}+w \frac{\partial T}{\partial z}\right] \\
& =k\left[\frac{\partial^{2} T}{\partial x^{2}}+\frac{\partial^{2} T}{\partial y^{2}}+\frac{\partial^{2} T}{\partial z^{2}}\right]
\end{aligned}
$$

The emissivity and absorptivity of a gray surface are independent of the wavelength. For a diffuse surface, the reflectivity is independent of the outgoing (or incoming) directions. The energy exchange between two surfaces depends on their size, separation distance, and orientation. The influences of these parameters are accounted by a view factor. The main assumption of the S2S model is that the absorption, emission, scattering of radiation by the air have not considered. Therefore, only "surface-to-surface" radiation is considered for the analysis. The emissivity of the internal cavity surface is considered as 0.89 so as to compare the results with available data, as the geometry considered for study is relatively new and no experimental data is available for similar geometry. The numerical procedure is validated for the cylindrical open cavity receiver experiment performed by E. Abbasi et.al [16].
The radiant flux from a given surface consists of directly emitted and reflected energy. The reflected energy flux is dependent on the incident energy flux from the surroundings, which then can be expressed in terms of the energy flux leaving all other surfaces. The energy reflected from surface $i$ is given by equation 6 .

$$
q_{o u t_{i}}=\varepsilon_{i} \sigma T_{i}{ }^{4}+\left(1-\varepsilon_{i}\right) q_{i n_{i}}
$$

2.3 Boundary Conditions: The constant heat flux boundary condition was applied to the cavity wall. Normal Velocity and gradient of all flow variables were set to zero across the vertical plane of symmetry. The inclination of the cavity was simulated by redirecting the gravity vector to desired direction. The gravitational constant was specified to standard value of $9.81 \mathrm{~m} / \mathrm{s}^{2}$. To prevent conduction heat loss from the receiver, the outer surface of the receiver was covered with ceramic wool. The receiver is exposed to ambient air, hence pressure inlet boundary condition was applied to the outer domain.

2.3.1 Constant heat flux: A constant heat flux of 4400 $\mathrm{W} / \mathrm{m}^{2}$ is given through the curved cylindrical and bottom surface.

2.3.2 Pressure inlet boundary condition: The outer domain is treated as pressure inlet boundary condition.

$$
\mathrm{P}=\mathrm{P}_{\mathrm{atm}}
$$

The following assumptions have been considered to solve the combined natural convection and surface radiation of modified cavity receiver.

(a) The temperature of the fluid is same as the surface temperature.

(b) The internal surfaces of the receiver are grey and diffuse.

2.4. Grid Independency: It is obvious that the heat interaction data will depend upon the mesh quality and the density of grid. Hence, setting the result independent of grid size is important. To compare the deviation occurring in Nusselt distribution profile with the use of various grid sizes, area averaged Nusselt number is calculated for different grid geometries. During the process of meshing, the edge size of steel in contact with the air is subjected to number of division and growth rate.

Table 1: Comparison of area average Nusselt number for different grid sizes

\begin{tabular}{|c|c|c|}
\hline Grid Nodes & $\begin{array}{c}\text { Computed } \\
\mathrm{Nu}_{\text {avg }}\end{array}$ & $\begin{array}{c}\text { Percentage } \\
\text { deviation with } \\
\text { preceding value }\end{array}$ \\
\hline 299860 & 82.03 & - \\
\hline 626339 & 90.435 & 10.24 \\
\hline 761694 & 91.326 & 0.985 \\
\hline
\end{tabular}




\section{VALIDATION OF NUMERICAL PROCEDURE}

The geometry considered for study is relatively new and no experimental data is available for similar geometry. The numerical procedure is validated with the experimental data for the cylindrical open cavity receiver experiment performed by E. Abbasi et.al [16].

3.1 Temperature profile: E. Abbasi [16] had plotted a temperature distribution along the top surface of the cylindrical cavity with dimensions:- Length:-166mm,

Inner diameter $-83 \mathrm{~mm}$, Thickness $-3 \mathrm{~mm}$ made up of stainless steel-316. The numerical temperature distribution obtained for present case was compared with E. Abbasi [16] and is shown in figure 3 .

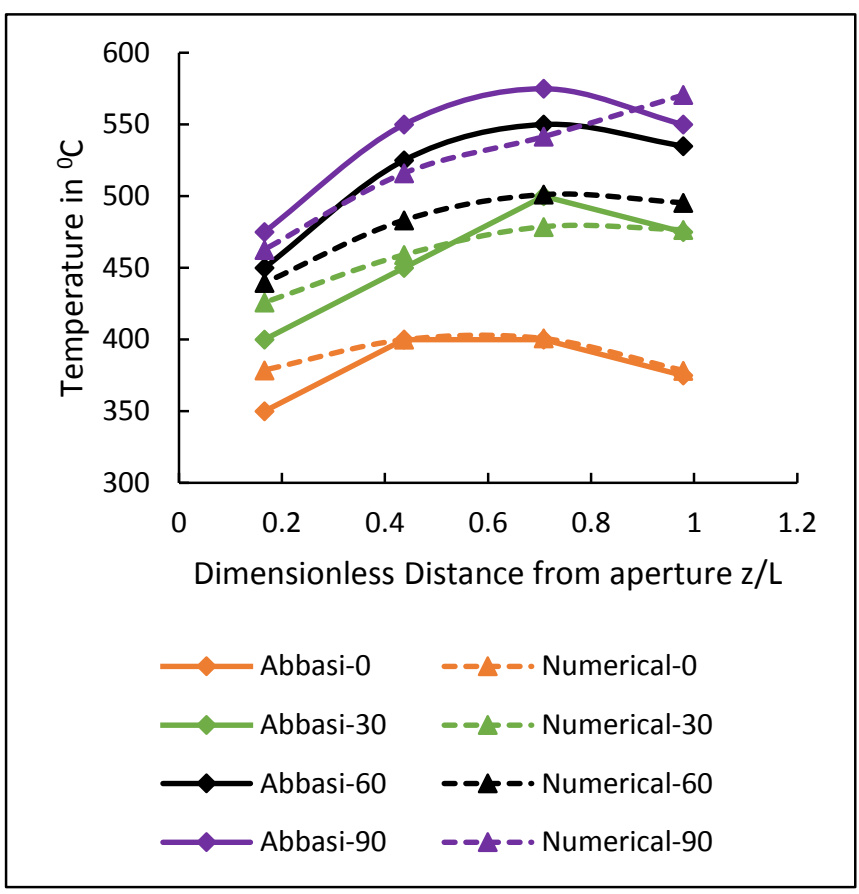

Figure 3 Comparison of surface temperature distribution inside the cavity

A maximum deviation of $8.89 \%$ is observed for sixty degree inclination at dimensionless distance of 0.7 from the aperture, with respect to experimentation done by E. Abbasi [16] which validates the numerical procedure adopted for the present study.

3.2 Radiation Heat loss:Figure 4 shows the comparison of radiation heat loss based on area weighted average temperature for present case and the Abbasi results with side heating only. Radiation loss is found to be same for lower inclinations with present model and increasing radiative losses at $60^{\circ}$ and $90^{\circ}$ inclinations. This may be due to increased cavity surface temperatures as a result of reduced convection losses. The convection losses may get reduced due to increase in stagnation zone area at higher inclinations as a result of additional inside cylinder. The increased surface area due to inner cylinder may also cause the radiative losses to increase.

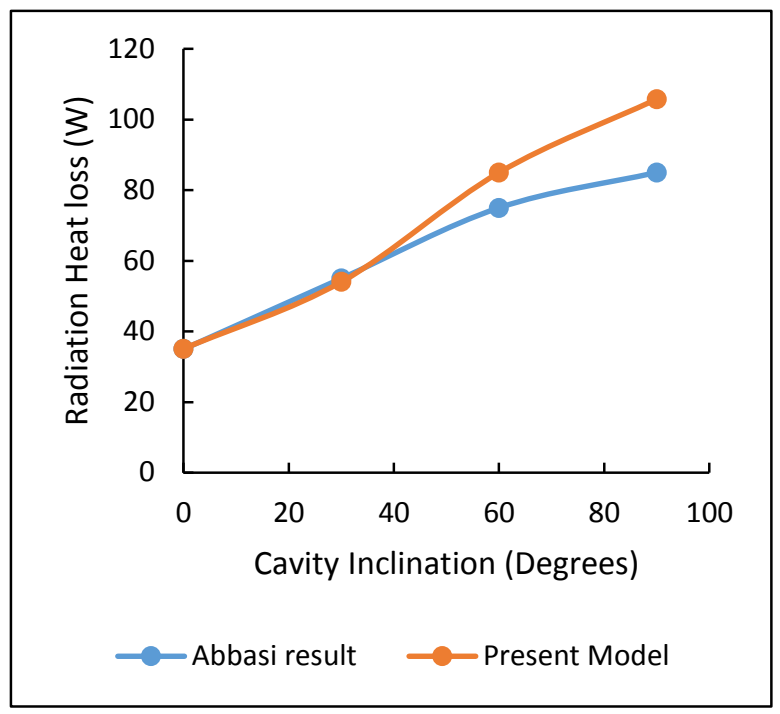

Figure 4 Comparison of radiation losses

\section{RESULTS}

The natural convection and surface radiation heat losses from the cascaded cavity receiver were estimated for different inclinations and temperatures. A 2D numerical analysis of receiver was carried out for positive inclination $(\theta)$ angles of $0^{\circ}$ (cavity aperture facing sideways) to $90^{\circ}$ (cavity aperture facing down).

4.1 Temperature Contours: The temperature contours for various inclination angles of $0^{0}$ to $90^{\circ}$ for cascaded receiver are shown in figure 5 (a) to (d).

As the receiver inclination changes from $0^{0}$ to $90^{\circ}$, the stagnant zone gradually increases in the receiver. At receiver inclination $90^{\circ}$, the entire cavity is filled with a stagnant zone. Increasing the stagnant air zone in the receiver decreases the convective heat loss from $0^{0}$ to $90^{\circ}$. The maximum convection heat loss occurs at $\theta=0^{0}$ and decrease gradually to $90^{\circ}$. Thus, the convective heat loss changes substantially with the inclination of the cavity receiver which is in line with the results of the previous numerical and experimental studies.

Figure 6 shows the temperature variation along the top inner surface of the cavity for the cascaded cavity. Highest temperatures are observed for the $90^{\circ}$ inclination because convection losses are supressed as the air flow become stagnant. The temperature of the base surface is slightly less compared to the maximum temperature for that inclination which is because of the heat conduction to the inside cylinder attached to the base. 


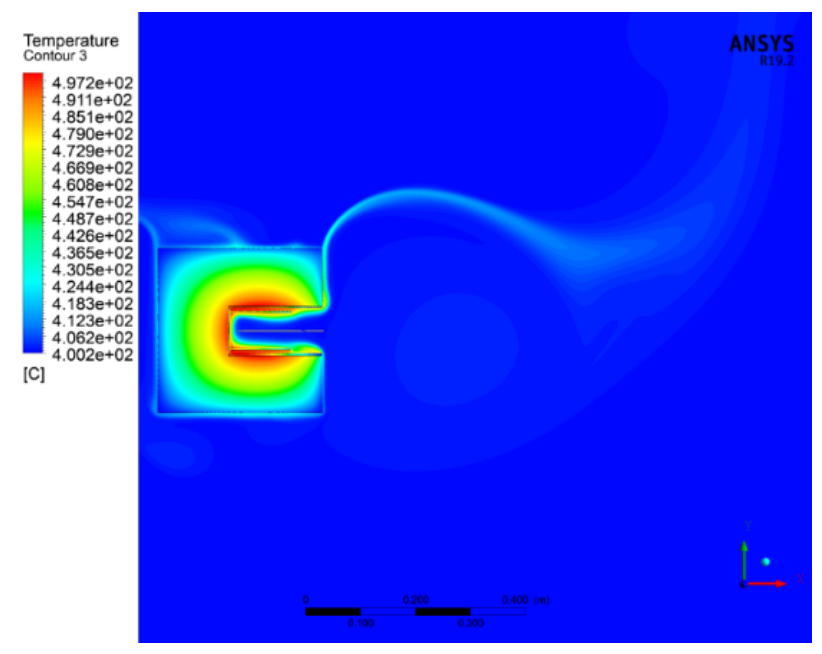

a) $0^{0}$

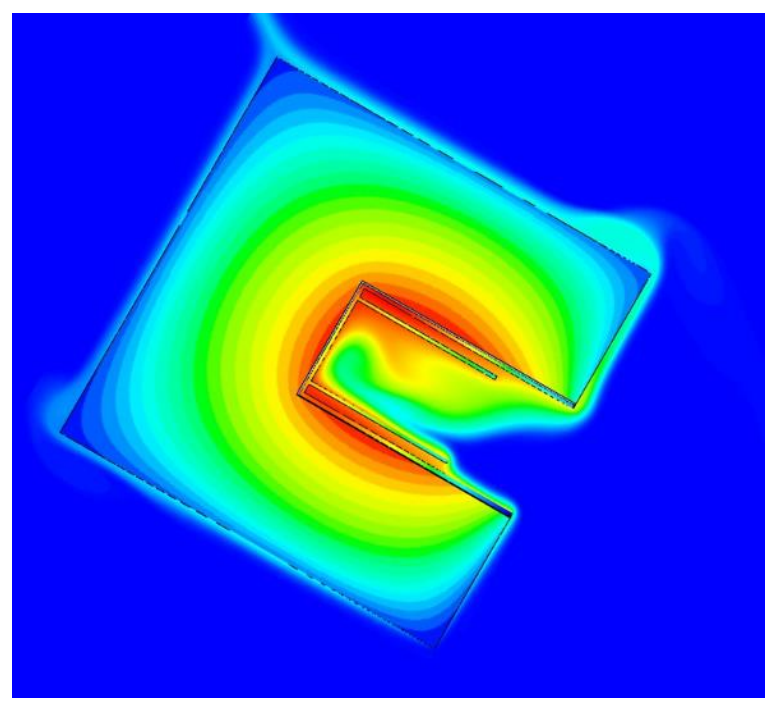

b) $30^{\circ}$

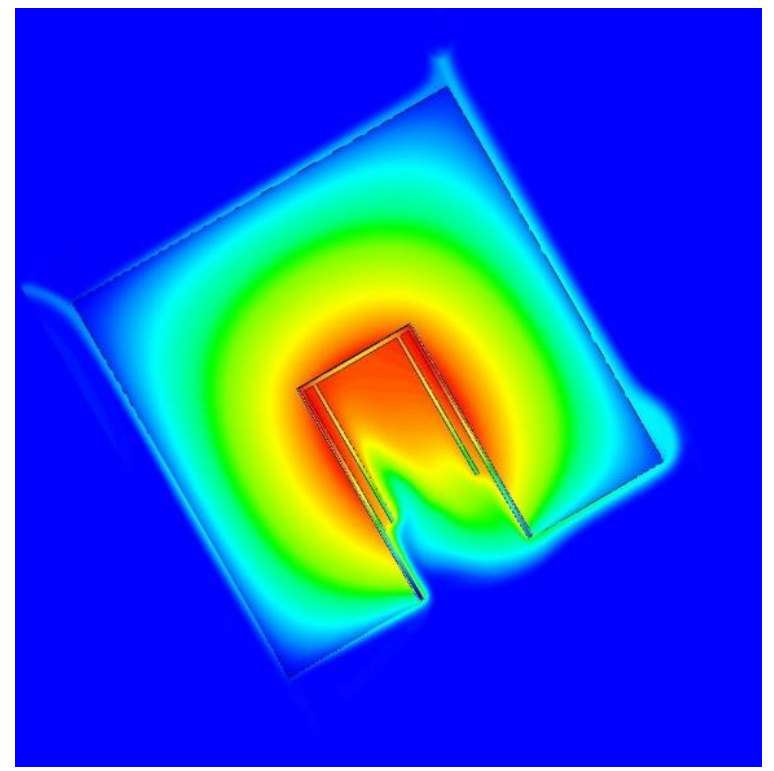

c) $60^{0}$

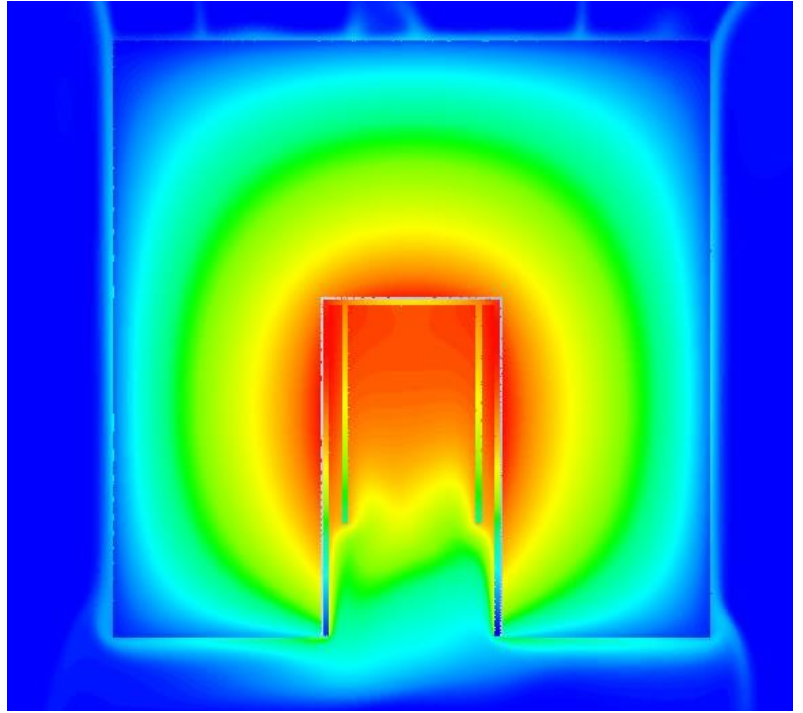

d) $90^{\circ}$

Figure 5 Temperature contours of the modified cavity receiver at cavity inclinations from $0^{\circ}$ to $90^{\circ}$

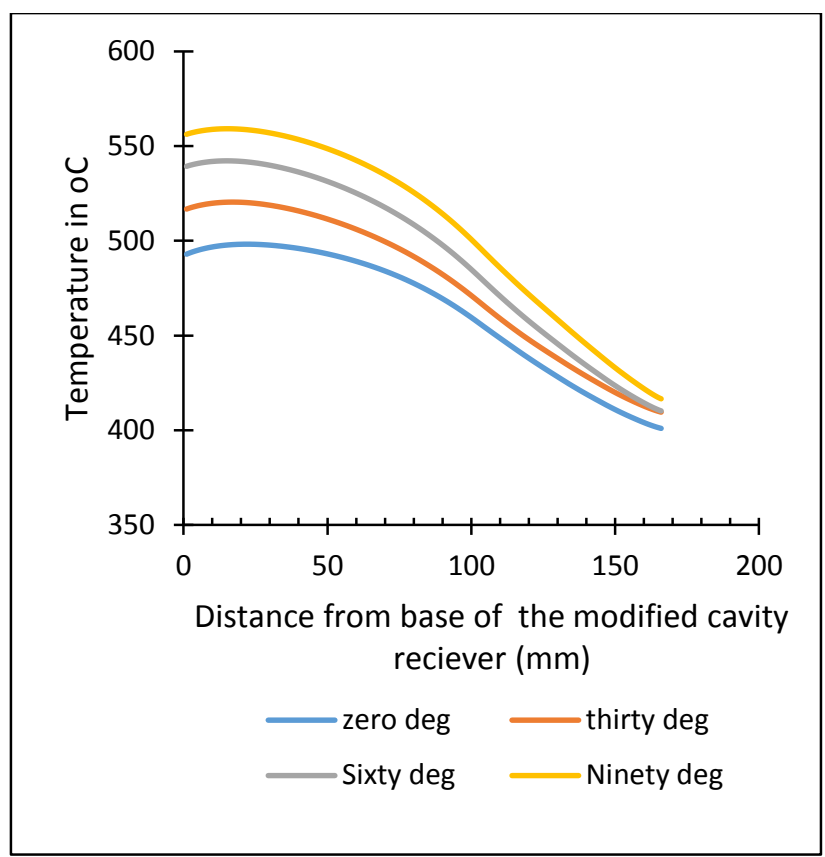

Figure 6 Temperature profile along the length of the receiver for various inclinations

4.2 Convection Heat Loss: The convection heat loss from the present model is compared with the heat loss in the cavity receiver model used by E. Abbasi [16], by applying the heat flux of $4400 \mathrm{~W} / \mathrm{m}^{2}$ with similar insulated outer boundary conditions and both side and bottom surface heating. Figure 7 shows the comparison of the convection heat loss for present cavity and that of $E$. Abbasi [16]. The convective heat losses are calculated using the energy balance between the input heat supply and the different modes of heat losses from the cavity. 


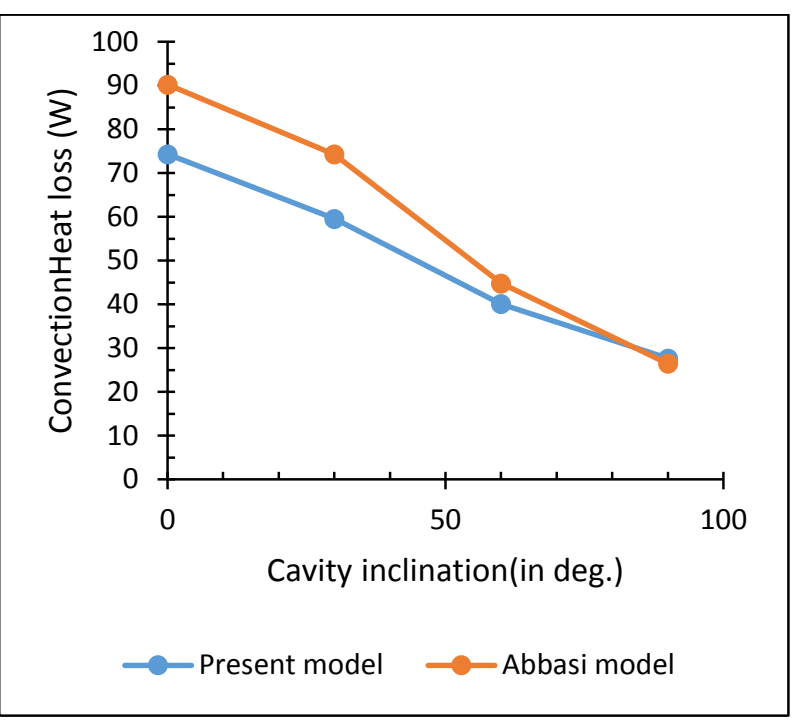

Figure 7 Comparison of Convective heat loss for various inclinations.

It is observed that as the cavity inclination increases from $0^{0}$ to $90^{0}$ the convection heat loss decreases, which follows the general trend as observed in literature. But as compared to the single cavity receiver used by E. Abbasi [16], the present model of cascaded cavity receiver shows less convective heat loss. This decreased convection loss for present cascaded cavity may be due to the increased obstruction to the convective air flow through the cavity offered by the inner cylinder increasing the stagnation zone compared to the simple cavity receiver.

4.3 Radiation heat loss: Figure 8 shows the comparison of numerical results for radiation heat loss from present cascaded cavity and that of E. Abbasi [16] under similar boundary conditions and both side and bottom surface heating.

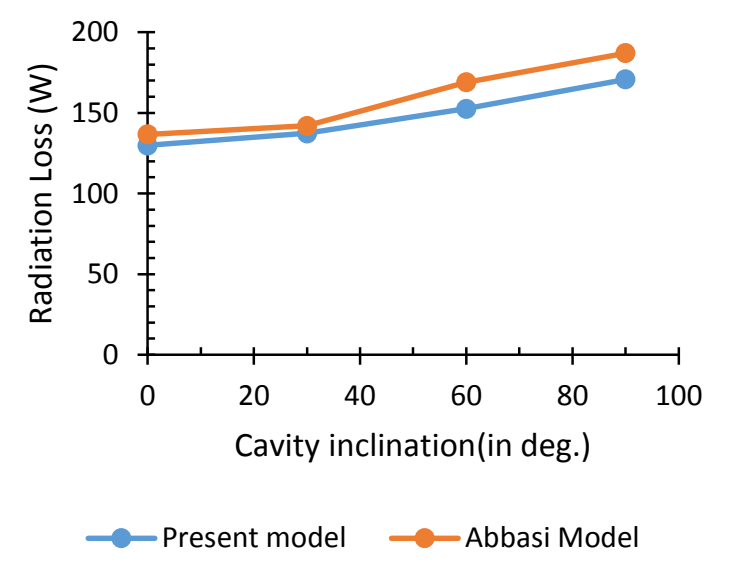

Figure 8 Comparison of radiation heat loss for various inclinations
The radiation losses are calculated from the radiation flux obtained from the numerical results. Though the temperature of the cavity surface increases as compared to the normal cavity the radiation heat losses are observed to reduce may be because of the cylinder in cylinder geometry of the cascaded receiver is affecting the view factor and causing the radiation to get trapped inside the cavity.

\section{CONCLUSIONS}

A 2D numerical analysis of receiver was carried out for positive inclination $(\theta)$ angles of $0^{\circ}$ (cavity aperture facing sideways) to $90^{\circ}$ (cavity aperture facing down). The numerical model is validated with the experimental results of E. Abbasi [16] and maximum deviation of $8.89 \%$ is observed for $60^{\circ}$ inclination. The numerical results for cascaded cavity receiver are compared with that of the normal receiver under similar boundary conditions of insulation and both side and bottom surface heating. The convection heat losses are observed to get reduced to maximum of $18 \%$ at $0^{0}$ inclination, with increased stagnation zone which is as per the expectation. The radiation heat losses are reduced up to $9 \%$ at higher inclinations though the temperatures are increased compared to normal receiver which may be due to cylinder in cylinder arrangement blocking the radiations inside and another reason may be the same cavity opening area though cavity surface area is increased in proposed design.

This work is supported by Veermata Jijabai Technological Institute, Mumbai, India. The authors are thankful to Director, VJTI and Mechanical Engineering Department.

\section{REFRENCES}

\begin{tabular}{|l|l|}
\hline 1. & $\begin{array}{l}\text { R. D. Jilte, S. B. Kedare \& J. K. Nayak, "Natural } \\
\text { Convection and Radiation Heat Loss from Open } \\
\text { Cavities of Shapes and Sizes Used with Dish } \\
\text { Concentrator." Mechanical Engineering Research } \\
\text { (Canadian Center of Science and Education) 3 (1). }\end{array}$ \\
\hline 2. & $\begin{array}{l}\text { M. Prakash, S. B. Kedare, and J. K. Nayak, } \\
\text { "Investigations on heat losses from a solar cavity } \\
\text { receiver." Solar Energy 83 (2): 157-170 (2009) }\end{array}$ \\
\hline 3. & $\begin{array}{l}\text { N. Sendhil Kumar, K. S. Reddy, "Numerical } \\
\text { investigation of natural convection heat loss in } \\
\text { modified cavity receiver for fuzzy focal solar dish } \\
\text { concentrator." Solar Energy 81: 846-855 (2007) }\end{array}$ \\
\hline 4. & $\begin{array}{l}\text { T. Taumoefolau, S. Paitoonsurikarn, G. Hughes, } \\
\text { and K. Lovegrove, "Experimental investigation of } \\
\text { natural convection heat loss from model solar } \\
\text { concentrator cavity receiver." Journal of Solar } \\
\text { Energy Engineering 126 (2): 801-807 (2004). }\end{array}$ \\
\hline 5. & $\begin{array}{l}\text { K. Lovegrove and S. Paitoonsurikarn, "A new } \\
\text { correlation for predicting the free convection loss } \\
\text { from solar dish concentrating." Solar: (ANZSES } \\
\text { '06). Canberra Australia (2006) }\end{array}$ \\
\hline 6. & $\begin{array}{l}\text { L.L. Eyler, "Predictions of convective losses from } \\
\text { a solar cavity receiver." DOE/SERI/SNLL } \\
\text { Workshop on Convective Losses from Solar }\end{array}$ \\
\hline
\end{tabular}




\begin{tabular}{|c|l|}
\hline & $\begin{array}{l}\text { Receivers Sandia Laboratory Report SAND81- } \\
\text { 8014. Livermore, California. 93-104 (1981). }\end{array}$ \\
\hline 7. & $\begin{array}{l}\text { A. M. Clausing, "An analysis of convective losses } \\
\text { from cavity solar central receivers." Solar Energy } \\
\text { 27 (4): 295-300 (1981). }\end{array}$ \\
\hline 8. & $\begin{array}{l}\text { P. LeQuere, F. Penot, M. Mirenayat, } \\
\text { "Experimental study of heat loss through natural } \\
\text { convection from an isothermal cubic open cavity" } \\
\text { Sandia: Sandia Laboratory Report (1981). }\end{array}$ \\
\hline 9. & $\begin{array}{l}\text { C. Balaji, S.P. Venkateshan, "Interaction of } \\
\text { radiation with free convection in an open cavity." } \\
\text { Int. J. Heat Fluid Flow 15 (4): 317-324 (1994). }\end{array}$ \\
\hline 10. & $\begin{array}{l}\text { N. Ramesh, W. Merzkirch, "Combined convective } \\
\text { and radiative heat transfers in side-vented open } \\
\text { cavity." Int. J. Heat Fluid Flow 22: 180-187 } \\
\text { (2001). }\end{array}$ \\
\hline 11. & $\begin{array}{l}\text { N. Singh, S.P. Venkateshan "Numerical study of } \\
\text { natural convection with surface radiation in side- } \\
\text { vented open cavities." Int. J. Thermal Sci. 43 (4): } \\
\text { 865-876 (2004). }\end{array}$ \\
\hline 12. & $\begin{array}{l}\text { J.F. Hinojosa, R.E. Cabanillas, G. Alvarez, C.E. } \\
\text { Estrada, "Nusselt number for the natural } \\
\text { convection and surface thermal radiation in a } \\
\text { square tilted open cavity." Int. Comm. Heat Mass } \\
\text { Transfer 32: 1184-1192 (2005). }\end{array}$ \\
\hline 13. & $\begin{array}{l}\text { C. Balaji, S.P. Venkateshan, "Correlations for free } \\
\text { convection and surface radiation in a square } \\
\text { cavity." Int. J. Heat Fluid Flow 15 (3): 249-251 } \\
\text { (1994). }\end{array}$ \\
\hline 14. & $\begin{array}{l}\text { K. S. Reddy. N. Sendhil Kumar, "Study of } \\
\text { combined natural convection and surface radiation } \\
\text { in a modified cavity receiver for solar parabolic } \\
\text { dish collector," in 1st National Conference on } \\
\text { Advances in Energy Research, AER-2006, IITB, } \\
\text { Macmillan, New Delhi (2006). }\end{array}$ \\
\hline 15. & $\begin{array}{l}\text { J. L. M. Jiji, Heat Convection. Verlag: Springer } \\
\text { (2006). }\end{array}$ \\
\hline 16. & $\begin{array}{l}\text { E. Abbasi-Shavazia, G.O. Hughes, J.D. Pye, } \\
\text { "Investigation of heat loss from a solar cavity } \\
\text { receiver" Energy Procedia 69: 269-275 (2015). }\end{array}$ \\
\hline
\end{tabular}

